\title{
AVALIAÇÃO DO POTENCIAL EROSIVO E CARIOGÊNICO DE SUCOS ARTIFICIAIS EM PÓ
}

\section{EVALUATION OF EROSIVE AND CARIOGENIC POTENTIAL OF ARTIFICIAL SOFT DRINKS}

\author{
Ana Keila Soares* \\ Brenda Bonvini** \\ Maria Mercês Aquino Gouveia Farias***
}

\begin{abstract}
RESUMO
Esta pesquisa objetivou avaliar o potencial erosivo e cariogênico de sucos artificiais em pó disponíveis comercialmente. Foram analisados 4 sabores (laranja, limão, maracujá, uva), de 4 marcas comerciais, distribuídos em 4 grupos (G-I, G-II, G-III, G-IV). Para a mensuração do pH inicial utilizou-se um potenciômetro e eletrodo combinado de vidro. Para a verificação da acidez titulável foram coletados $100 \mathrm{ml}$ de cada sabor, adicionandose alíquotas de $100 \mu \mathrm{L}$ de $\mathrm{NaOH} 1 \mathrm{~N}$, até alcançar $\mathrm{pH} 5,5$. A quantificação dos Sólidos Solúveis Totais ( ${ }^{\circ}$ Brix) foi realizada por refratometria. Os resultados foram submetidos à Análise de Variância (ANOVA). As comparações das médias foram realizadas pelo teste Tukey em um nível de $5 \%$ de significância $(p<0,05)$. Todas as bebidas apresentaram valores de $\mathrm{pH}$ inferiores a 5,5. Não houve diferenças estatisticamente significantes de $\mathrm{pH}$ entre os sabores de uma mesma marca comercial, exceto o sabor uva da marca Mid®. Houve diferenças significantes de $\mathrm{pH}$ entre os mesmos sabores de marcas comerciais diferentes. Ao se comparar um mesmo

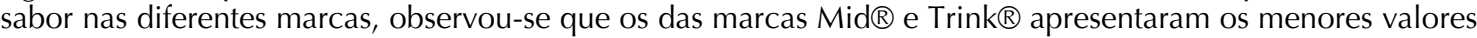
de acidez titulável,. O sabor limão da marca La Frutta Nestle® apresentou a maior acidez titulável. Em relação ao Brix, ocorreram variações do teor de açúcar no mesmo sabor nas diferentes marcas comerciais, exceto o sabor uva. Considerando-se a marca comercial, apenas a marca Trink® não apresentou variações do grau Brix. Concluiu-se que todas as bebidas analisadas são potencialmente erosivas e cariogênicas, podendo contribuir para a etiologia da cárie e erosão dental.
\end{abstract}

Descritores: Erosão dentária • Cárie dentária • Acidez.

\section{ABSTRACT}

This research investigated the erosive and cariogenic potential of artificial juices powders available commercially. Were analyzed four flavors of artificial juices (orange, lemon, passion fruit, grapefruit), of five trademarks, divided into 4 groups (G-I, G-II, G-III, G-IV). To measure the initial pH it was used a pot and combined electrode glass. To check the titratable acidity were collected $100 \mathrm{ml}$ of each flavor, adding aliquots of $100 \mathrm{~mL}$ of $1 \mathrm{~N} \mathrm{NaOH}$, until pH 5,5. The quantification of Total Soluble Solids ( ${ }^{\circ}$ Brix) was made by refractometry. The results were statistically analyzed by analysis of variance test (ANOVA). Comparisons of averages were performed by the Tukey test, at a $5 \%$ level of significance $(p<0,05)$. All reviewed juices showed $\mathrm{pH}$ values below 5.5. There weren't statistically significant differences among the flavors of the same trademark. Except the grape flavor of the Mid® trademark. However, there were significant differences between different flavors of the same

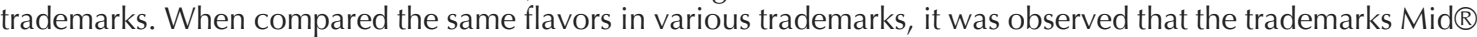
and Trink $₫$ had the lowest titratable acidity. The lemon flavor Nestle $₫$ brand La Frutta presented higher acidity. Regarding to Brix, there were variations in the sugar content in the same flavor in different brands, except the grape flavor. Considering the trademark, just Trink® brand showed no variations of Brix. It was concluded that all drinks are considered potentially erosive and cariogenic, and may contribute to the etiology of dental caries and dental erosion.

Descriptors: Tooth Erosion Dental Caries • Acidity.

\footnotetext{
* Acadêmica, Bolsista de Iniciação Científica do Curso de Odontologia da Universidade do Vale de Itajaí (UNIVALI), Itajaí/SC, Brasil. E-mail: anakeila_ soares@hotmail.com

** Acadêmica, Bolsista de Iniciação Científica do Curso de Odontologia da Universidade do Vale de Itajaí (UNIVALI), Itajaí/SC, Brasil. E-mail: bren_dika@ hotmail.com

*** Mestre em Odontopediatria, Professora da Disciplina de Clínica integrada Infantil do Curso de Graduação em Odontologia da Universidade do Vale de Itajaí (UNIVALI), Itajaí/ SC, Brasil. E-mail: mercesfarias@gmail.com
} 
SOARES AK

BONVINI B

FARIAS MMAC

AVALIAÇÃO DO

POTENCIAL

EROSIVO E

CARIOGENICO

DE SUCOS

ARTIFICIAIS EM

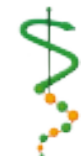

REV, ODONTOL,

UNIV, CID, SÃO

PAULO

$2014 ; 26(3): 197-$

203, SET-DEZ

\section{INT RODUÇ ÃO}

A variedade e a oferta de alimentos industrializados influenciam os hábitos alimentares da população, especialmente a infantil, pois nessa fase os padrões alimentares são instituídos ${ }^{1}$. Crianças são expostas ao intenso apelo comercial de produtos industrializados, amplamente ofertados em supermercados e cantinas ${ }^{2}$. O consumo frequente e abundante desses alimentos pode afetar a saúde nesse período e na idade adulta, uma vez que muitos alimentos industrializados são ricos em gorduras, carboidratos refinados e ácidos. Somando-se a isto, a ingestão de alimentos industrializados pode estimular a redução do consumo de alimentos naturais 1,3 .

Diversos estudos têm demonstrado o potencial erosivo e cariogênico de bebidas industrializadas ${ }^{4-8}$.

O termo clínico erosão dental é usado para descrever os efeitos físicos de uma perda localizada, crônica e patológica de tecido mineral dentário (esmalte e dentina) removido quimicamente da superfície dentária por meio de ácidos ou substâncias quelantes, sem envolvimento bacteriano 9 . Por outro lado, a cárie dentária desenvolve-se a partir da presença do biofilme dental, responsável por mediar a desmineralização dos tecidos dentários duros ${ }^{10}$. Ambas têm etiologia multifatorial e a dieta representa um importante fator. Na cárie, pela presença de sacarose e outros carboidratos fermentáveis nos alimentos e bebidas ${ }^{10}$. Na erosão dental, pela presença de ácidos na composição dos alimentos e bebidas. ${ }^{5}$

A relação existente entre o consumo de alimentos açucarados industrializados e cárie já é bem estabelecida. ${ }^{10}$ Estudos recentes apontam uma preocupação com a prevalência da erosão dental e sua relação com hábitos dietéticos em escolares brasileiros, cujos achados relacionam o consumo abusivo de alimentos ácidos com o aumento do risco para o desenvolvimento da erosão dental. ${ }^{11-15}$

Dessa forma, é importante que se conheça sobre o potencial erosivo e cariogênico de bebidas industrializadas para que possamos orientar seu consumo de forma racional, especialmente por crianças que apresentam comportamento de risco perante a cárie e erosão dental.

Assim, o objetivo deste estudo foi investigar o potencial erosivo e cariogênico de sucos artificiais em pó disponíveis comercialmente.

\section{MÉTODOS}

Foram analisados 4 sabores (laranja, limão, maracujá, uva) de sucos artificiais em pó, de 4 marcas comerciais. Cada marca compôs um grupo (G-I, G-II, G-III, G-IV) (Quadro1).

Foram obtidos em supermercados 3 embalagens de cada sabor. Realizou-se a mensuração do $\mathrm{pH}$ inicial após diluição do suco em pó conforme as instruções do fabricante, sob temperatura ambiente. Do suco diluído, coletaram-se 3 amostras de $30 \mathrm{ml}$ para leitura do $\mathrm{pH}$. Para esses ensaios, utilizou-se um potenciômetro e eletrodo combinado de vidro (Tec-2 Tecnal) previamente calibrado com soluções padrão $\mathrm{pH}$ 7,0 e $\mathrm{pH} 4,0$, antes de cada leitura.

Para a verificação da acidez titulável (capacidade tampão), foram coletadas 3 amostras de $100 \mathrm{ml}$ de cada sabor, adicionando-se alíquotas de $100 \mu \mathrm{L}$ de $\mathrm{NaOH}$ $1 \mathrm{~N}$, sob agitação constante (Agitador Magnético Fisaton), medindo-se subsequentemente o $\mathrm{pH}$, até se atingir pH 5,5.

A quantificação dos Sólidos Solúveis Totais ( ${ }^{0}$ Brix) foi realizada em triplicata, por refratometria, e foram utilizadas 2 gotas de cada produto e com o auxílio de um refratômetro específico de campo, com faixa de leitura ${ }^{0}$ Brix de $0 \approx 32 \%$ e precisão de 0,2 , obteve-se o valor do ${ }^{0}$ Brix dos produtos selecionados.

Os resultados foram submetidos à análise estatística através da Análise de Variância (ANOVA). As comparações das médias foram realizadas pelo teste Tukey, em um nível de 5\% de significância $(p<0,05)$.

\section{RESULTADOS}

Todas as bebidas avaliadas apresentaram valores de $\mathrm{pH}$ inferiores a 5,5 (Tabela $1)$.

Não houve diferenças estatisticamente significantes de $\mathrm{pH}$ entre os sabores 
Quadro1. Composição dos produtos segundo fabricantes.

\begin{tabular}{|c|c|c|}
\hline Grupos & Sabores & Composição \\
\hline \multirow{4}{*}{$\begin{array}{l}\text { G-I Tang } \\
\text { (Kraft } \\
\text { Foods }{ }^{\circledR} \text { ) }\end{array}$} & Laranja & $\begin{array}{l}\text { Ácido cítrico, açúcar, ferro, vitaminas C e A, polpa de laranja } \\
\text { desidratada }(1 \%)\end{array}$ \\
\hline & Limão & $\begin{array}{l}\text { Ácido cítrico, açúcar, ferro, vitaminas C e A, polpa de limão } \\
\text { desidratada ( } 1 \%)\end{array}$ \\
\hline & Maracujá & $\begin{array}{l}\text { Ácido cítrico, açúcar, ferro, vitaminas C e A, polpa de maracujá } \\
\text { desidratada }(1 \%)\end{array}$ \\
\hline & Uva & $\begin{array}{l}\text { Ácido cítrico, fumárico, açúcar, ferro, vitaminas C e A, polpa de } \\
\text { uva desidratada ( } 1 \%)\end{array}$ \\
\hline \multirow{4}{*}{$\begin{array}{l}\text { G-II } \\
\text { Trink } \\
\text { (Parati®) }\end{array}$} & Laranja & $\begin{array}{l}\text { Ácido cítrico, açúcar, vitaminas C, polpa de laranja desidratada } \\
(1 \%)\end{array}$ \\
\hline & Limão & $\begin{array}{l}\text { Ácido cítrico, açúcar, vitaminas C, polpa de limão desidratada } \\
(1 \%)\end{array}$ \\
\hline & Maracujá & $\begin{array}{l}\text { Ácido cítrico, açúcar, vitaminas C, polpa de maracujá desid- } \\
\text { ratada }(1 \%)\end{array}$ \\
\hline & Uva & $\begin{array}{l}\text { Ácido cítrico, açúcar, vitaminas C, polpa de uva desidratada } \\
(1 \%)\end{array}$ \\
\hline \multirow{4}{*}{$\begin{array}{l}\text { G-III } \\
\text { (MID) } \\
\text { (Ajino- } \\
\text { moto®) }\end{array}$} & Laranja & $\begin{array}{l}\text { Ácido cítrico, açúcar, vitaminas C, Polpa de laranja desidratada } \\
(1 \%)\end{array}$ \\
\hline & Limão & $\begin{array}{l}\text { Ácido cítrico, açúcar, vitaminas C, polpa de limão desidratada } \\
(1 \%)\end{array}$ \\
\hline & Maracujá & $\begin{array}{l}\text { Ácido. cítrico, açúcar, vitaminas C, polpa de maracujá desid- } \\
\text { ratada }(1 \%)\end{array}$ \\
\hline & Uva & $\begin{array}{l}\text { Ácido cítrico, açúcar, vitaminas C, polpa de uva desidratada } \\
(1 \%)\end{array}$ \\
\hline \multirow{4}{*}{$\begin{array}{l}\text { G-IV } \\
\text { La Frutta } \\
\text { Nestle } \\
\text { (Nestle®) }\end{array}$} & Laranja & $\begin{array}{l}\text { Ácido cítrico, açúcar, vit. C, A, B2, B6, B1, ác. fólico niacina, } \\
\text { ferro, ác. pantotênico, polpa de laranja desidratada (1\%) }\end{array}$ \\
\hline & Limão & $\begin{array}{l}\text { Ácido cítrico, açúcar, Vit. C, A, B2, B6, B1, ác. fólico niacina, } \\
\text { ferro, ác. pantotênico, polpa de limão desidratada (1\%) }\end{array}$ \\
\hline & Maracujá & $\begin{array}{l}\text { Ácido cítrico, açúcar, vit. C, A, B2, B6, B1, ác. fólico niacina, } \\
\text { ferro, ác. pantotênico, polpa de maracujá desidratada (1\%) }\end{array}$ \\
\hline & Uva & $\begin{array}{l}\text { Ácido cítrico, fumárico, açúcar, vit. C, A, B2, B6, B1, ác. fólico } \\
\text { niacina, ferro, ác. pantotênico, polpa de uva desidratada ( } 1 \%)\end{array}$ \\
\hline
\end{tabular}

SOARES AK

BONVINI B

FARIAS MMAC

AVALIAÇÃo DO

POTENCIAL

EROSIVO E

CARIOGENICO

DE SUCOS

ARTIFICIAIS EM PÓ

Fonte: fabricante.

Tabela 1. Valores médios de $\mathrm{pH}$

\begin{tabular}{lcccc}
\hline \hline Sabores & G-I $($ Tang® $)$ & G-II (Trink $\left.{ }^{\circledR}\right)$ & G-III (Mid®) & G-IV (La Frutta Nestle $\left.{ }^{\circledR}\right)$ \\
\hline Uva & $3,18 \mathrm{~A} \mathrm{a}$ & $2,86 \mathrm{~B} \mathrm{a}$ & $3,32 \mathrm{~A} \mathrm{a}$ & $2,90 \mathrm{~B} \mathrm{a}$ \\
Laranja & $3,21 \mathrm{~A} \mathrm{a}$ & $2,72 \mathrm{C} \mathrm{a}$ & $3,07 \mathrm{AB} \mathrm{b}$ & $2,99 \mathrm{~B} \mathrm{a}$ \\
Maracujá & $3,20 \mathrm{~A} \mathrm{a}$ & $2,73 \mathrm{~B} \mathrm{a}$ & $3,17 \mathrm{~A} \mathrm{~b}$ & $2,87 \mathrm{~B} \mathrm{a}$ \\
Limão & $3,12 \mathrm{~A} \mathrm{a}$ & $2,89 \mathrm{BC} \mathrm{a}$ & $3,02 \mathrm{AB} \mathrm{b}$ & $2,81 \mathrm{C} \mathrm{a}$ \\
\hline \hline
\end{tabular}

Letras iguais, maiúsculas nas linhas e minúsculas nas colunas, não diferem significativamente entre si pelo teste de Tukey $(p<0,05)$

de uma mesma marca comercial, exceto o sabor uva da marca Mid®. Entretanto, houve diferenças significantes de pH entre os mesmos sabores de marcas comerciais diferentes (Tabela 1).

Para a acidez titulável, ao analisar as marcas comerciais, observou-se que os sabores da marca Mid® não apresentaram entre si diferenças estatísticas. Nas demais marcas houve diferenças entre alguns dos sabores analisados (Tabela 2).

Ao se comparar um mesmo sabor nas diversas marcas, observou-se que os das

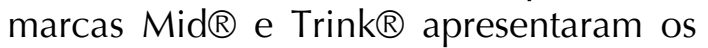
menores valores de acidez titulável, semelhantes entre si e diferentes significan-
REV, ODONTOL. UNIV, CID, SÃO PAULO

$2014 ; 26(3): 197-$ 203, SET-DEZ 
SOARES AK

BONVINI B

FARIAS MMAC

AVALIAÇÃO DO

POTENCIAL

EROSIVO E

CARIOGENICO

DE SUCOS

ARTIFICIAIS EM

PÓ

200

REV, ODONTOL.

UNIV. CID . SÃO

PAULO

$2014 ; 26(3): 197-$

203, SET-DEZ

Tabela 2. Volumes médios de $\mathrm{NaOH} 1 \mathrm{~N}$ para alcançar $p H 5,5$

\begin{tabular}{ccccc}
\hline \hline Sabores & G-I (Tang®) & G-II (Trink®) & G-III (Mid® $\left.{ }^{\circledR}\right)$ & G-IV (La Frutta Nestle $\left.{ }^{\circledR}\right)$ \\
\hline Uva & $2600,00 \mathrm{~B} \mathrm{~b}$ & $3033,33 \mathrm{~B} \mathrm{a}$ & $1133,33 \mathrm{C} \mathrm{a}$ & $3700,00 \mathrm{~A} \mathrm{~b}$ \\
Laranja & $3166,67 \mathrm{~A} \mathrm{~b}$ & $1366,67 \mathrm{~B} \mathrm{~b}$ & $1133,33 \mathrm{~B} \mathrm{a}$ & $3300,00 \mathrm{~A} \mathrm{~b}$ \\
Maracujá & $3766,67 \mathrm{~A} \mathrm{a}$ & $1266,67 \mathrm{~B} \mathrm{~b}$ & $1200,00 \mathrm{~B} \mathrm{a}$ & $3600,00 \mathrm{~A} \mathrm{~b}$ \\
Limão & $4266,67 \mathrm{~B} \mathrm{a}$ & $1266,67 \mathrm{C} \mathrm{b}$ & $1566,67 \mathrm{C} \mathrm{a}$ & $5200,00 \mathrm{~A} \mathrm{a}$ \\
\hline \hline
\end{tabular}

Letras iguais, maiúsculas nas linhas e minúsculas nas colunas, não diferem significativamente entre si pelo teste de Tukey $(p<0,05)$

Tabela 3. Valores médios dos sólidos solúveis totais ${ }^{\circ}$ Brix

\begin{tabular}{ccccc}
\hline \hline Sabores & G-I (Tang $\left.{ }^{\circledR}\right)$ & G-II (Trink® $)$ & G-III (Mid® $)$ & G-IV (La Frutta Nestle $\left.{ }^{\circledR}\right)$ \\
\hline Uva & 0,152 A b & 0,155 A a & $0,158 \mathrm{~A} \mathrm{a}$ & $0,152 \mathrm{~A} \mathrm{~b}$ \\
Laranja & $0,163 \mathrm{~A} \mathrm{a}$ & $0,158 \mathrm{~A} \mathrm{a}$ & $0,143 \mathrm{~B} \mathrm{~b}$ & $0,153 \mathrm{AB} \mathrm{b}$ \\
Maracujá & $0,162 \mathrm{~A} \mathrm{a}$ & $0,153 \mathrm{~B} \mathrm{a}$ & $0,143 \mathrm{~B} \mathrm{~b}$ & $0,162 \mathrm{~A} \mathrm{a}$ \\
Limão & $0,147 \mathrm{AB} \mathrm{b}$ & $0,157 \mathrm{~A} \mathrm{a}$ & $0,142 \mathrm{~B} \mathrm{~b}$ & $0,150 \mathrm{~A} \mathrm{~b}$ \\
\hline \hline
\end{tabular}

Letras iguais, maiúsculas nas linhas e minúsculas nas colunas, não diferem significativamente entre si pelo teste de Tukey $(p<0,05)$

temente dos demais, exceto o sabor uva.

Destacamos o comportamento do sabor limão da marca La Frutta Nestle® por apresentar a maior acidez titulável entre os sabores, diferindo significativamente das outras marcas comerciais.

Em relação ao Brix, observaram-se variações do teor de açúcar no mesmo sabor nas diferentes marcas comerciais, exceto o sabor uva. Considerando-se a marca comercial, apenas a marca Trink ${ }^{\circledR}$ não apresentou variações do grau ${ }^{0}$ Brix entre os diferentes sabores (Tabela 3).

\section{I SCUSSÃO}

O aumento da disponibilidade e do consumo de bebidas industrializadas, em países desenvolvidos e em desenvolvimento, tem sido acompanhado pela crescente consciência da população dos potenciais danos relacionados ao seu consumo frequente ${ }^{16 .}$ A dieta desempenha um importante papel no desenvolvimento da cárie dentária e erosão dental, sendo que o estabelecimento de hábitos alimentares saudáveis tem grande importância na sua prevenção. ${ }^{10,16}$

Os preparados artificiais sólidos para refresco ou sucos artificiais em pó são parte integrante da rotina de consumidores brasileiros, uma vez que são de fácil preparo, alto rendimento e baixo custo. O que os torna muito atrativos para as populações de baixa renda. ${ }^{17}$ Estudo recente apontou o consumo de sucos artificiais em pó como a bebida industrializada mais consumida pelas crianças atentidas na clínica de Odontopediatria da Universidade do Vale do Itajaí. ${ }^{8}$

A dieta ácida inclui os ácidos cítrico, fosfórico, fumárico, ascórbico, málico, tartárico, oxálico e carbônico, presentes em sucos de frutas naturais e artificiais, frutas, refrigerantes e vinagres, e são uma das principais causas da erosão dental. ${ }^{16}$ Diversos fatores estão associados ao potencial erosivo de uma bebida, sendo que, dentre os fatores químicos, o $\mathrm{pH}$, a acidez titulável, tipo de ácido e o teor de cálcio, fosfato e fluoretos são os mais relevantes. ${ }^{18,19}$

Deve-se destacar que os sucos industrializados comumente apresentam vários componentes químicos, entre eles alguns ácidos atuando como antioxidantes, tal como o ácido ascórbico e reguladores de pH, como o ácido cítrico. A presença desses componentes pode ter relação com o desenvolvimento de lesões de erosão dental e reações alérgicas. ${ }^{20,21}$

Nas bebidas analisadas observou-se que todas apresentavam valores de $\mathrm{pH}$ inferiores a 5,5, considerado crítico para dissolução do esmalte. Este achado corrobora com diversos estudos que mensuraram a acidez de preparados sólidos para refrescos. ${ }^{8,22-24} \mathrm{O}$ tipo de ácido próprio da fruta interfere na acidez da bebida, porém nas bebidas industrializadas vários ácidos podem ser acrescidos artificialmente durante o processamento industrial. Nesse sentido, nas bebidas analizadas observou-se como característica em comum, segundo informação do fabricante, a pre- 
sença dos ácidos cítrico e ascórbico em todas elas. Esse achado é relevante, pois o ânion citrato resultante da dissociação do ácido cítrico, age como um quelante de íons de cálcio, aumentando a desmineralização do esmalte dentário. Disso resulta um efeito desmineralizante mesmo após o pH na superfície dentária estar normalizado. ${ }^{18,19}$

Em relação à acidez titulável, as bebidas analisadas apresentaram variada capacidade tampão intrínseca. Destacamos o comportamento do sabor limão da marca comercial La Frutta Nestle ${ }^{\circledR}$, por apresentar um dos menores valores de $\mathrm{pH}$ e mais elevada acidez titulável. Estudo recente demonstrou que a acidez titulável de uma bebida influencia o $\mathrm{pH}$ salivar, mais do que o pH. ${ }^{25}$ Como consequência da elevada acidez titulável há aumento do tempo para que a saliva neutralize o ácido, provocando diferenças quanto ao potencial erosivo de uma bebida mesmo dentro de uma mesma faixa de $\mathrm{pH} .{ }^{19}$

Por outro lado, a presença de sacarose nos alimentos e bebidas tem forte impacto no estabeleciamento da cárie dental. ${ }^{10}$

A cariogenicidade dos alimento está relacionada ao tipo de carboidrato, sua consistência física (líquida ou sólida), frequência de consumo, momento de ingestão, forma de ingestão, dentre outros fatores. ${ }^{26} \mathrm{~A}$ quantificação de Sólidos Solúveis Totais (SST) através da refratometria na escala Brix se constitui em um método descrito e utilizado na literatura cientifica. ${ }^{23,27}$ A leitura da percentagem do ${ }^{\circ}$ Brix deve ser semelhante à concentração real de açúcar existente nas soluções analisadas. ${ }^{24}$.

Nas bebidas selecionadas neste estudo, apenas o sabor uva apresentou quantidade semelhante de sólidos solúveis totais independente da marca comercial. Nos demais sabores houve variação signifi- cativa do teor de sólidos solúveis totais, nas diferentes marcas. Da mesma forma, destacamos o comportamento da marca Trink ${ }^{\circledR}$, por exibir a mesma quantidade de sólidos solúveis totais independente do sabor. Estudos anteriores também demonstraram a presença de sólidos solúveis totais nos preparados artificiais para refresco. ${ }^{23,24}$

Compreendendo a importância dos profissionais da saúde como uma visão integral do paciente, devemos orientá-los quanto ao consumo das bebidas industrializadas, considerando seus efeitos sobre as estruturas dentárias e sobre o organismo. Nesse sentido, segundo o Guia Alimentar para a População Brasileira, o consumo de frutas deve ser sempre privilegiado ao invés do sucos, mesmo os naturais, pois parte dos nutrientes e fibras são perdidos durante seu preparo, orientando seu consumo apenas em uma das refeições diárias. Além disso, é recomendado que se evite o consumo de sucos industrializados, pois são alimentos ultraprocessados, pobres em nutrientes, ricos em aditivos, que têm como função estender a duração dos produtos, dotá-los de propriedades sensoriais (cor, aroma, sabor, textura) e torná-los extremamente atraentes. ${ }^{28}$

\section{CONCLUSÕES}

Todas as bebidas analisadas são potencialmente erosivas e cariogênicas, podendo contribuir para a etiologia da cárie e erosão dental, na dependência de seu padrão de ingestão.

\section{AGRADECIMENTOS}

Ao Programa de Iniciação Científica ProBIC/UNIVALI e a Vice-Reitoria de Pesquisa, Pós-Graduação, Extensão e Cultura da Universidade do Vale do Itajaí, que financiou a pesquisa.
SOARES AK

BONVINI B

FARIAS MMAC

AVALIAÇÃo DO

POTENCIAL

EROSIVO E

CARIOGENICO

DE SUCOS

ARTIFICIAIS EM $P O ́$

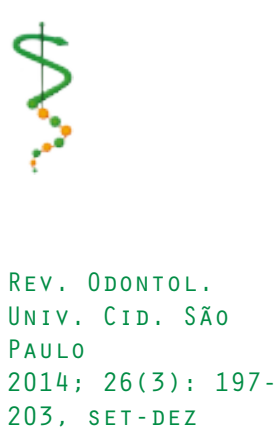


SOARES AK

BONVINI B

FARIAS MMAC

AVALIAÇÃO DO

POTENCIAL

EROSIVO E

CARIOGENNICO

DE SUCOS

ARTIFICIAIS EM

$P O ́$

202

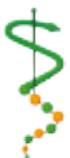

REV, ODONTOL,

UNIV. CID, SÃO PAULO

$2014 ; 26(3): 197-$

203, SET-DEZ:

\section{REFERENNCIAS}

1. Saldiva SRDM, Escuder MM, Mondini L, Levy RB, Venancio SI. Práticas alimentares de crianças de 6 a 12 meses e fatores maternos associados. Jornal de Pediatria 2007 jan/fev;83(1):

2. Gambon DL, Brand HS, Veerman EC. Dental erosion in the 21st century: what is happening to nutritional habits and lifestyle in our society? Br Dent J 2012 Jul;213(2):55-7.

3. Stewart KF, Fairchild RM, Jones RJ, Hunter L, Harris C, Morgan MZ. Children's understandings and motivations surrounding novelty sweets: a qualitative study. Int J Paediatr Dent 2013 Nov;23(6):424-34.

4. Dantas RVF, Valença AMG, Claudino LV, LIma AL, Carvajal JCL, Costa GF. Características físico-químicas da dieta líquida cafeinada. Pesq Bras Odontoped Clin Integr 2008 8(3):333-36.

5. Farias MMAG, Bernardi M, Silva Neto R, Tames DR, Silveira EG, Bottan ER. Avaliação de propriedades erosivas de bebidas industrializadas acrescidas de soja em sua composição. Pesq Bras Odontoped Clin Integr 2009 9(3):277-81.

6. Farias MMAG, Ozelame SB, Schmitt BHE, Capristano DF, Silveira EG. Avaliação da acidez de diversas marcas de leite fermentado disponíveis comercialmente. Pesqui Bras Odontopediatria Clin Integr 2012 dez;12(4):451-5.

7. Silva JG, Farias MMAG, Silveira EG, Schmitt BHE, Araújo SM. Mensuração da acidez de bebidas não lácteas destinadas ao público infantil. Rev Odontol UNESP 2012 mar/abr;41(2):76-80.

8. Farias MMAG, Marques JS, Schmitt BHE, Silveira EG, Araújo SM. Avaliação da acidez da dieta líquida ingerida pelos pacientes da clínica de odontopediatria da UNIVALI. RFO UPF 2014 19(2):145-50.

9. Magalhaes AC, Wiegand A, Rios D, Honorio HM, Buzalaf MA. Insights into preventive measures for dental erosion. J Appl Oral Sci 2009 MarApr; 17(2):75-86.
10. Losso EM, Tavares MC, Silva JY, Urban Cde A. Severe early childhood caries: an integral approach. J Pediatr (Rio J) 2009 Jul-Aug;85(4):295-300.

11. Waterhouse PJ, Auad SM, Nunn JH, Steen IN, Moynihan PJ. Diet and dental erosion in young people in southeast Brazil. Int J Paediatr Dent 2008 Sep;18(5):353-60.

12. Correr GM, Alonso RC, Correa MA, Campos EA, Baratto-Filho F, Puppin-Rontani RM. Influence of diet and salivary characteristics on the prevalence of dental erosion among 12-year-old schoolchildren. J Dent Child (Chic) 2009 Sep-Dec;76(3):181-7.

13. Nahas Pires Correa MS, Nahas Pires Correa F, Nahas Pires Correa JP, Murakami C, Mendes FM. Prevalence and associated factors of dental erosion in children and adolescents of a private dental practice. Int J Paediatr Dent 2011 Nov;21(6):451-8.

14. Murakami C, Oliveira LB, Sheiham A, Nahas Pires Correa MS, Haddad AE, Bonecker M. Risk indicators for erosive tooth wear in Brazilian preschool children. Caries Res 2011 45(2):121-9.

15. Farias MMAG, Silveira EG, Schmitt BHE, Araújo SM. Prevalência da erosão dental em crianças e adolescentes brasileiros. SALUSVITA 2013 32(2):187-98.

16. Auad S, Moynihan P. Diet and dental erosion. Quintessence Int 2007 Feb;38(2):130-3.

17. INMETRO INdM, Qualidade e Tecnologia. Preparado sólido artificial para refresco (pó para refresco). 2012 [Acesso em 201322 fevereiro 2013]; Disponível em: http://www.inmetro. gov.br/consumidor/produtos/refresco. asp.

18. Furtado JR, Freire VC, Messias DCF, Turssi CP. Aspectos físico-químicos relacionados ao potencial erosivo de bebidas ácidas. RFO UPF 2010 15(3):325-30. 
19. Lussi A, Jaeggi T. Chemical factors. Monogr Oral Sci 2006 20(77-87.

20. Touyz LZ. The acidity $(\mathrm{pH})$ and buffering capacity of Canadian fruit juice and dental implications. J Can Dent Assoc 1994 May;60(5):454-8.

21. Oliveira CH, Binotti RS, Quagliara PC, Rebechi M. Substâncias químicas presentes em sucos de frutas em pó comercializados no Brasil Rev Bras Alergia Imunopatol 2006 maio/ jun;29(3):127-32.

22. Corso S, Padilha D, Corso A, Hugo F. Avaliação do potencial erosivo de sucos de frutas artificiais em pó, refrigerantes, isotônicos e chás enlatados disponíveis comercialmente no Brasil. RFO UPF 2006 11(1):45-50.

23. Catão MHCV, Silva ADL, Oliveira RM. Propriedades físico-químicas de preparados sólidos para refrescos e sucos industrializados. RFO UPF 2013 18(1):12-7.
24. Cardoso AMR, Santos AMS, Almeida FWB, Albuquerque TP, Xavier AFC. Características físico-químicas de sucos de frutas industrializados: estudo in vitro. Odonto 2013 21(41-42):9-17.

25. Tenuta LMA, Fernandez CE, Brandao ACS, Cury JA. Titratable acidity of beverages influences salivary $\mathrm{pH}$ recovery. Braz Oral Res 2015 29(1):

26. Guedes-Pinto AC, Bonecker M, Rodrigues CDM. Fundamentos de odontologia: odontopediatria. São Paulo: Santos; 2009.

27. Almeida LFD, Abílio GMF, Cavalcante MT, Castro DR, Cavalcanti A. Cariogenic and erosive potential of industrialized fruit juices available in Brazil. Braz J Oral Sci 2010 9(3):351-57.

28. Brasil Ministério da Saúde. Guia Alimentar para a população brasileira 2014 [Acesso em 201426 julho 2014]; Disponível em: http://www. foodpolitics.com/wp-content/uploads/ Brazils-Dietary-Guidelines_2014.pdf.

Recebido em 11/03/2015

Aceito em 15/04/2015
SOARES AK

BONVINI B

FARIAS MMAC

AVALIAÇÃO DO

POTENCIAL

EROSIVO E

CARIOGENICO

DE SUCOS

ARTIFICIAIS EM PÓ

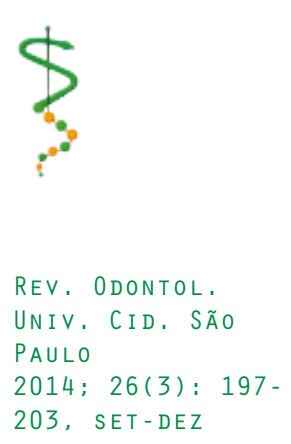

